\title{
Lung ageing and COPD: is there a role for ageing in abnormal tissue repair?
}

\author{
Corry-Anke Brandsma ${ }^{1,2}$, Maaike de Vries ${ }^{2,3}$, Rita Costa ${ }^{4}$, Roy R. Woldhuis ${ }^{1,2}$, \\ Melanie Königshoff ${ }^{4,5,6}$ and Wim Timens ${ }^{1,2,6}$
}

\author{
Number 5 in the Series "Pathology for the clinician" \\ Edited by Peter Dorfmüller and Alberto Cavazza
}

\begin{abstract}
Affiliations: ${ }^{1}$ University of Groningen, University Medical Center Groningen, Dept of Pathology and Medical Biology, Groningen, The Netherlands. ${ }^{2}$ University of Groningen, University Medical Center Groningen, Groningen Research Institute for Asthma and COPD (GRIAC), Groningen, The Netherlands. ${ }^{3}$ University of Groningen, University Medical Center Groningen, Dept of Epidemiology, Groningen, The Netherlands. ${ }^{4}$ Comprehensive Pneumology Center. Helmholtz Zentrum München, University Hospital of the Ludwig Maximilians University, Munich, Germany. ${ }^{5}$ Division of Pulmonary Sciences and Critical Care Medicine, Dept of Medicine, University of Colorado, Denver, CO, USA. ${ }^{6}$ Both authors contributed equally.
\end{abstract}

Correspondence: Corry-Anke Brandsma, University of Groningen, University Medical Center Groningen, Dept of Pathology and Medical Biology, Hanzeplein 1, 9713 GZ Groningen, The Netherlands.

E-mail: c.a.brandsmadumcg.nl

@ERSpublications

Several ageing hallmarks are present in COPD and indicate a role for (abnormal) ageing in tissue repair in COPD http://ow.ly/OLtW30gE3ct

Cite this article as: Brandsma C-A, de Vries M, Costa R, et al. Lung ageing and COPD: is there a role for ageing in abnormal tissue repair? Eur Respir Rev 2017; 26: 170073 [https://doi.org/10.1183/16000617.00732017].

ABSTRACT Chronic obstructive pulmonary disease (COPD) is the fourth leading cause of death worldwide, with increasing prevalence, in particular in the elderly. COPD is characterised by abnormal tissue repair resulting in (small) airways disease and emphysema. There is accumulating evidence that ageing hallmarks are prominent features of COPD. These ageing hallmarks have been described in different subsets of COPD patients, in different lung compartments and also in a variety of cell types, and thus might contribute to different COPD phenotypes. A better understanding of the main differences and similarities between normal lung ageing and the pathology of COPD may improve our understanding of the mechanisms driving COPD pathology, in particular in those patients that develop the most severe form of COPD at a relatively young age, i.e. severe early-onset COPD patients.

In this review, after introducing the main concepts of lung ageing and COPD pathology, we focus on the role of (abnormal) ageing in lung remodelling and repair in COPD. We discuss the current evidence for the involvement of ageing hallmarks in these pathological features of COPD. We also highlight potential novel treatment strategies and opportunities for future research based on our current knowledge of abnormal lung ageing in COPD.

Previous articles in this series: No. 1: Ghigna MR, Mooi WJ, Grünberg K. Pulmonary hypertensive vasculopathy in parenchymal lung diseases and/or hypoxia. Eur Respir Rev 2017; 26: 170003. No. 2: Bubendorf L, Lantuejoul S, de Langen AJ, et al. Nonsmall cell lung carcinoma: diagnostic difficulties in small biopsies and cytological specimens. Eur Respir Rev 2017; 26: 170007. No. 3: Rossi G, Cavazza A, Spagnolo P, et al. The role of macrophages in interstitial lung diseases. Eur Respir Rev 2017; 26: 170009. No. 4: Ohshimo S, Guzman J, Costabel U, et al. Differential diagnosis of granulomatous lung disease: clues and pitfalls. Eur Respir Rev 2017; 26: 170012.

Received: June 232017 | Accepted after revision: Sept 202017

Conflict of interest: Disclosures can be found alongside this article at err.ersjournals.com

Provenance: Commissioned article, peer reviewed.

Copyright OERS 2017. ERR articles are open access and distributed under the terms of the Creative Commons Attribution Non-Commercial Licence 4.0. 


\section{What is ageing?}

As the word indicates, ageing is a process that mainly affects elderly people. With the rapidly growing elderly population, the negative aspects of ageing are becoming increasingly apparent. Ageing is defined as a progressive decline in homeostasis after the reproductive phase is complete, which results in increased risk of disease or death [1]. As such, ageing is one of the main driving forces of the development and increasing burden of noncommunicable diseases, i.e. chronic diseases. Worldwide, noncommunicable diseases are the leading cause of mortality and responsible for 38 million deaths each year. Of these deaths, 4 million can be attributed to respiratory diseases [2]. In many of the noncommunicable diseases, including ischaemic heart disease, diabetes, Alzheimer's disease and chronic obstructive pulmonary disease (COPD), it is proposed that acceleration of the normal ageing process is involved in disease pathogenesis [3].

In this review we will first describe the processes involved in the normal ageing lung and the disease pathology of COPD and then summarise the similarities and differences. We will specifically focus on the role of abnormal ageing in lung remodelling and repair in COPD and discuss the current evidence for ageing hallmarks in the pathological features of COPD. Finally, we will discuss potential novel treatment strategies based on the current evidence for lung ageing in COPD.

\section{The ageing lung}

On average, the human lung is growing until the age of 10-12 years and matures further until it reaches its maximum function at the age of $\sim 20$ years of age for females and $\sim 25$ years for males [4]. From then on, lung function progressively declines with increasing age as a consequence of structural and physiological changes to the lung [4].

We can broadly divide the structural changes of the ageing lung into three categories: changes in lung structure, changes in the chest wall and changes in respiratory muscles [5]. The changes in the structure of the lung are mainly attributed to an increase in the size of the alveolar space without any inflammation or alveolar wall destruction, so-called "senile emphysema". This microscopic emphysema increases in a linear fashion with age in nonsmokers, but in smokers a more progressive increase in alveolar space size can be observed in specific (susceptible) individuals only [6-8]. Senile emphysema might be a consequence of loss of the supporting structure of the lung parenchyma [4,5]. Additionally, it has been observed that the elastic recoil of the lung reduces with increasing age. It has been postulated that this phenomenon is caused more by reduced surface tension forces from the alveoli due to increased individual diameter size than by changes in elastin and collagen in the lung parenchyma [5]. With increasing age, the compliance of the chest wall decreases progressively, which can be explained by several, synergistically acting, age-related processes. First, the shape of the thorax may change with age due to reduced thickness of intervertebral discs, leading to reduced intrathoracic volume. Secondly, age-associated osteoporosis may cause vertebral fractures, resulting in changes in the shape of the thorax. Thirdly, the stiffness of the ribs increases with age, thereby enhancing the forces needed for movement of the chest [5, 9]. In general, muscle strength diminishes with age. This loss in muscle strength is also reflected in the diaphragm, the most important respiratory muscle, and thus affects the breathing pattern [5]. These structural changes in the ageing lung have a clear effect on overall lung function, and several physiological parameters are altered upon ageing. Both the forced expiratory volume in $1 \mathrm{~s}$ (FEV1) and forced vital capacity (FVC) decrease with age, and the rate of decline has been shown to be higher for males than for females. As a consequence of the reduced elastic recoil and compliance of the chest wall, the residual volume increases, while the vital capacity decreases [9]. Interestingly, the total lung capacity does not change with increasing age, because the reduction in elastic recoil observed upon ageing is counterbalanced by the decrease in chest wall compliance and muscle strength of the chest $[5,9]$. Although the distribution of alveolar ventilation and perfusion across the lungs is very heterogeneous as a consequence of the decline in alveolar surface area, density of lung capillaries and pulmonary capillary blood volume, the overall transfer capacity of the lung for carbon monoxide is reduced with increasing age. Clinically, this might influence physical activity and the development of sleep disordered breathing $[5,9]$.

As well as changes in lung function with increasing age, the natural defence mechanisms of the lungs also gradually become less functional, leading to increased infection risk [4]. For example, the antioxidant response to prohibit the accumulation of reactive oxygen species (ROS) deteriorates in the ageing lung, consistent with an increase in ROS levels upon ageing [10]. Furthermore, intercellular communications become less effective with ageing [11], contributing to two phenomena known as immunosenescence and inflammaging. The first of these relates to dampened immune responses following an infection or injury and the second relates to chronic activation of immune responses in aged subjects in the absence of a real immunological challenge [12]. As a result of immunosenescence, innate and adaptive immune responses decrease with age, characterised by an increase in memory and effector cells at the expense of naïve T-cells and the overall T-cell repertoire $[13,14]$. Of interest, several of the pro-inflammatory mediators associated 
with inflammaging, such as tumour necrosis factor (TNF)- $\alpha$, interleukin (IL)- $1 \beta$ and IL- 6 , are present as pro-inflammatory mediators in the senescence-associated secretory phenotype. Another factor contributing to increased inflammation in aged lungs is poor airway clearance of particles. Over time, muscles become atrophic, resulting in less strength for effective cough [15]. Also, mucociliary clearance is known to be compromised with age [16], which might in particular contribute to viral and bacterial inflammation and thus acute exacerbations of lung diseases like COPD.

\section{Pathology of COPD}

COPD is a heterogeneous disease involving both the alveolar and airway compartments, resulting in (small) airways disease and emphysema (figure 1). The extent of pathological changes in these different lung compartments varies in individual patients [17]. The aetiology, in general, involves exposure to external noxious particles or gases. In the Western world this is particularly a result of (cigarette) smoking and in the non-Western world it is mainly a result of indoor cooking. COPD pathology is driven by chronic inflammation [18-20], which continues to be observed after stopping smoking [21], even after $\geqslant 1$ years $[22,23]$. The combination of the exposure and inflammation leads to lung tissue damage, resulting in remodelling of the lung. This remodelling has remarkable features. A common main aetiology, smoke exposure, leads to fibrosis (extracellular matrix (ECM) increase), with thickening of (large and, in particular, small) airway walls and lumen reduction, and concurrently to emphysema, with ECM destruction in the lung parenchyma $[19,24]$. Another main histopathological feature of COPD is seen in the vasculature, in particular as an increased thickness of the arterioles, resulting in pulmonary hypertension as an important complication of COPD [25].

The chronic inflammation is mainly characterised by macrophages and $\left(\mathrm{CD} 8^{+}\right) \mathrm{T}$-cells, and can also show increased plasma cells, neutrophilic granulocytes and sometimes eosinophilic granulocytes [26-28]. B-cells are also found, often in aggregates or in small primary or secondary follicles [29-31]. These have been described in association with airways as tertiary follicles, or reactive bronchus-associated lymphoid tissue, but also have been observed scattered in the parenchyma [31, 32]. The presence of such follicles is variable, being most pronounced in patients with severe COPD [30, 32], but also seen, to a lesser extent, in heavy smokers without COPD [32]. As oligoclonality of these follicles has been shown [31], it is most likely that these are induced by local antigen stimulation [33-35]. Cigarette smoke components, microorganisms and matrix components [36] have been considered aetiological factors for this antigenic stimulation, but none has yet been convincingly shown [34, 37].

In the large and small airways, epithelial changes are observed, with an increase in goblet cells, basal cell hyperplasia and squamous metaplasia, sometimes with dysplasia [20, 38-40]. Overall, these changes are in general more pronounced in the large airways, where the primary and most intensive exposure takes place. In the airway lumen, increased and more sticky mucus can be present, which is produced by the increased
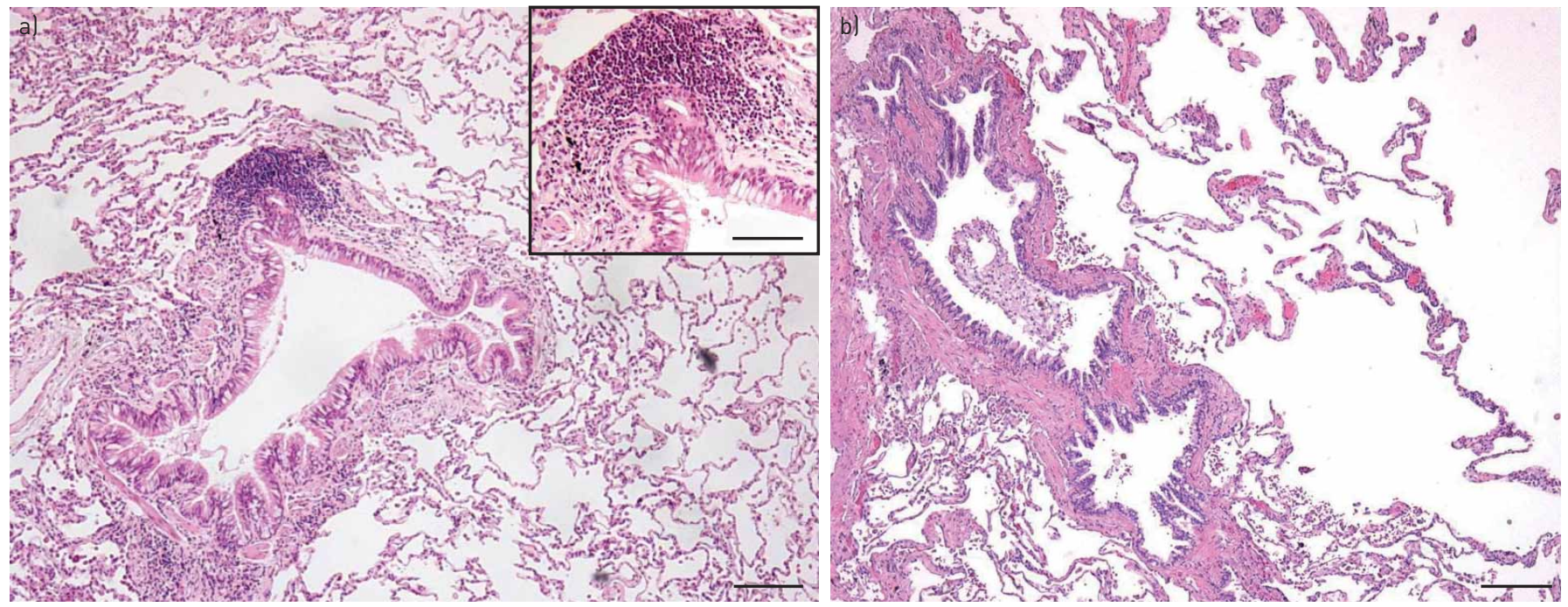

FIGURE 1 Pathological changes in chronic obstructive pulmonary disease. a) Characteristic picture of airways changes, with increase of goblet cells, a thickened airway wall with some adventitial inflammation, and a small lymphoid follicle at the left upper side. Emphysema is hardly present here. Haematoxylin and eosin, $\times 200$ magnification, scale bar=200 $\mu \mathrm{m}$. Inset shows magnification of part of the airway with a lymphoid follicle; scale bar $=50 \mu \mathrm{m}$. b) At the left, an almost longitudinal cross-section of a small airway, and at the right, severe parenchymal destruction by emphysema. Haematoxylin and eosin, $\times 100$ magnification, scale bar $=500 \mu \mathrm{m}$. 
number of goblet cells in combination with the enlarged mucus glands. The airway walls are thickened, caused by increased inflammation, an increase in smooth muscle mass, increase in size of the mucus glands and, in time, further changes with an increase in the ECM.

The matrix changes in the airways are in general of a fibrotic nature, with an increase in collagen in the submucosa but also in the adventitia of smaller airways [41-44]. Similar to asthma, a thickening of the basement membrane is seen, although it is more irregular and of a different composition [43]. An interesting finding was that in the peribronchial area of small airways in severe COPD an impressive reduction in proteoglycans is seen, particularly decorin and to a lesser extent biglycan [45, 46]. A main characteristic of decorin is that it can bind transforming growth factor- $\beta$, one of the main cytokines regulating matrix production, which is consistently upregulated in COPD [47, 48]. Another important feature is that decorin is the main proteoglycan connecting collagen fibrils, in this way regulating the rigidity of the collagen $[48,49]$. As decorin is reduced in COPD, this will result in a very loose type of fibrosis, contributing to increased airway collapsibility and reduced peribronchial tensile strength of the parenchymal attachments $[19,24]$. An interesting observation in a limited number of patients was a reduction in the number of small airways with increasing emphysema severity within COPD lungs, suggesting that part of the airflow limitation within COPD is primarily caused by destruction of small airways $[50,51]$.

Emphysema is the characteristic pathology of COPD occurring in the lung parenchyma. It is characterised by net destruction of alveolar walls as a result of increased destruction in combination with failing tissue repair [19]. The destructive part is caused by an imbalance between exposure to oxygen radicals from cigarette smoke and neutrophils and proteases from macrophages and neutrophils, and their counterparts, oxygen scavengers and antiproteases [52]. In the parenchyma, inflammation is also present, but far less research has been published about this compartment $[53,54]$. Similar to the airways, cytotoxic $\left(\mathrm{CD} 8^{+}\right)$ T-cells are important infiltrating cells in alveolar septa and arterioles in COPD when compared to non-COPD controls [53]. Whereas neutrophils were (and are) considered a main inflammatory cell contributing to emphysema, in early studies in smokers no association was found between parenchymal neutrophils and the severity of the destructive index [55]. In addition to possible direct effects of both smoke components and proteases released from inflammatory cells, indirect effects have been shown to destroy alveolar walls in COPD by inducing apoptosis of endothelial and alveolar type II epithelial cells, probably contributing to emphysema $[56,57]$.

The important vascular changes in COPD are mainly seen in the arterioles. Intimal thickening with smooth muscle proliferation and an increase in collagen and elastin, together with a hyperplastic increase of the media, have been observed [25, 58-61]. Initially this was thought to be the result of hypoxia, but these events are also present in mild and early cases [60]. More recently, the vascular changes have been attributed to "endothelial dysfunction", i.e. pathophysiological changes in the normal biochemical function of the endothelium $[25,61,62]$. The end result is arterioles with a thickened wall, increased contraction and reduced lumen, but also with a reduced ability to vasodilate. Functionally, this leads to pulmonary hypertension, which is a major cause of morbidity in COPD and a predictor of mortality $[25,61]$.

\section{Similarities and differences between lung ageing and COPD}

Early reports comparing senile lungs with normal and emphysematous lungs by VERBEKEN et al. [63, 64] demonstrated that airspace enlargement in ageing, although comparable with smoking-induced emphysema, differed in the fact that it was more regular in distribution, without clear-cut destruction. Furthermore, increased thickening of alveolar septa was observed without inflammation or fibrosis, with reduced density of the membranous bronchioles. They proposed the term "senile lung" for this condition. So, although similar in terms of the enlargement of airspaces, at least part of the pathogenesis appears to be different. Regarding loss of elasticity, it is less clear whether this is a destructive effect in COPD or whether in both conditions there is an underlying defect in elastin fibrillogenesis. The functional effects in small airways in milder forms of emphysema are, however, comparable with the senile lung, with loss of elastic recoil [64].

ITO and BARNES [1] proposed that with increasing age the lung is less able to maintain organ integrity and protect itself against oxidative injury. KIRKWOOD $[65,66]$ indicated that cellular defects often cause inflammatory reactions contributing to damage, thereby causing a vicious circle of ongoing microscopic damage with ageing. As yet, it is not readily clear to what extent these events are present during the total life course and when the effects on tissue homeostasis become effective. In addition, it is not clear what the variation in the natural course of these events is with regard to their contribution to deterioration of the normal ageing lung. Taking the aforementioned mechanisms into account, several components observed in COPD, such as ongoing inflammation, unbalanced oxidative stress and changes in the ECM, are quite comparable to those observed in the normal ageing lung. However in COPD, these changes will 
occur in general at an earlier age and to a larger extent compared to normal lung ageing. In the following paragraphs we will discuss in more detail whether premature or abnormal (lung) ageing aspects may or may not play a role in the pathogenesis and natural course of COPD.

\section{Lung ageing and COPD phenotypes}

As described, COPD is a very heterogeneous lung disease presenting different (mixed) phenotypes. Well-known phenotypes in COPD are chronic bronchitis, with predominant airway-related changes (inflammation and airway wall thickening) and increased mucus production, and emphysema with (severe) alveolar wall destruction, hyperinflation and impaired gas exchange. Other phenotypes of COPD are related to the number of exacerbations (i.e. the frequent exacerbator) [67,68] or the age of onset of the disease (i.e. severe early-onset COPD) [69]. Given the difference in underlying pathology of these phenotypes, it can be envisaged that lung ageing is more or differently involved in some of these phenotypes than others. As discussed, senile emphysema is an important hallmark of lung ageing and, together with structural changes, the ageing lung is in particular inclined to develop an emphysema-like phenotype. This is different from the bronchitis phenotype, where, apart from increased inflammation, there are very few similarities with the ageing lung and there is no indication of increased mucus production or airway wall thickening in the ageing lung, although decreased ciliary function with ageing probably contributes to increased coughing and decreased mucociliary clearance [15]. The frequent exacerbator is an interesting phenotype, as exacerbations are in general linked to infections and the susceptibility for infections increases with age [70, 71]. Moreover, age is a risk factor for COPD exacerbations [72] and hospital admissions for acute exacerbations of COPD [73].

Severe early-onset COPD is an interesting COPD phenotype with respect to ageing. Patients with this phenotype develop very severe COPD at a relatively young age (i.e. $<53$ years, according to SILVERMAN et al. [69]) and often with a relatively low number of pack-years of smoking. This severe early-onset COPD leads to a high personal burden and huge societal costs due to loss in working days and frequent hospitalisations. As these patients progress so quickly, we propose that, if accelerated ageing is an important contributor to COPD pathology, it should be most clear in these severe early-onset COPD patients. In terms of pathology, these patients are characterised by severe emphysema [69].

\section{Ageing hallmarks in COPD}

The main hallmarks of ageing were recently summarised in a review by LópEZ-OTín et al. [11] and this was followed by an overview of these hallmarks in lung ageing and lung disease [74]. Broadly, the ageing hallmarks can be divided into processes affecting transcription (genomic instability, telomere attrition and epigenetic alterations), processes affecting the metabolism (loss of proteostasis, deregulated nutrient sensing and mitochondrial dysfunction) and cellular processes (cellular senescence, stem cell exhaustion and altered intracellular communication). We will now discuss the current knowledge about the possible role for these ageing hallmarks in COPD and focus on findings in structural cells (alveolar and bronchial epithelial cells, smooth muscle cells and fibroblasts) and lung tissue. Subsequently, we will summarise the main evidence regarding the role of ageing hallmarks in disturbed repair and remodelling in COPD. All findings discussed in the following paragraphs are summarised in table 1.

\section{Transcription}

Genomic instability

Ageing leads to increased DNA damage and to an impaired ability to prevent and repair DNA damage. Several markers related to these features have also been demonstrated in COPD lungs and may contribute to the pathological processes.

The DNA damage marker gamma-H2A histone family member X $(\gamma-\mathrm{H} 2 \mathrm{~A} . \mathrm{X})$ has been found to be increased in alveolar walls, including type I and type II epithelial cells and endothelial cells [75], as well as in small airways of COPD patients compared to controls [75, 76]. Another study, however, showed no differences in small airways in COPD versus control [77].

Smoke exposure increases $\gamma$-H2A.X levels in experimental animal models, and cigarette smoke extract (CSE) treatment increases $\gamma$-H2A.X levels in bronchial epithelial cells and fibroblasts in vitro [76, 78, 79], suggesting an important role for oxidative stress. In addition, the anti-ageing protein sirtuin 6 (SIRT6) is considered to be protective against DNA damage and senescence. SIRT6 levels are decreased in lung tissue homogenates from COPD patients, and overexpression and knockdown of SIRT6 in bronchial epithelial cells resulted in a decrease and an increase in $\gamma \mathrm{H} 2 \mathrm{~A} . \mathrm{X}$ levels, respectively [79].

The DNA repair marker Ku86 was found to be decreased in parenchymal lung tissue of COPD patients, including small airways [77, 80], while no differences were observed in Ku70 expression in these samples. 
TABLE 1 Evidence for ageing hallmarks in chronic obstructive pulmonary disease (COPD)

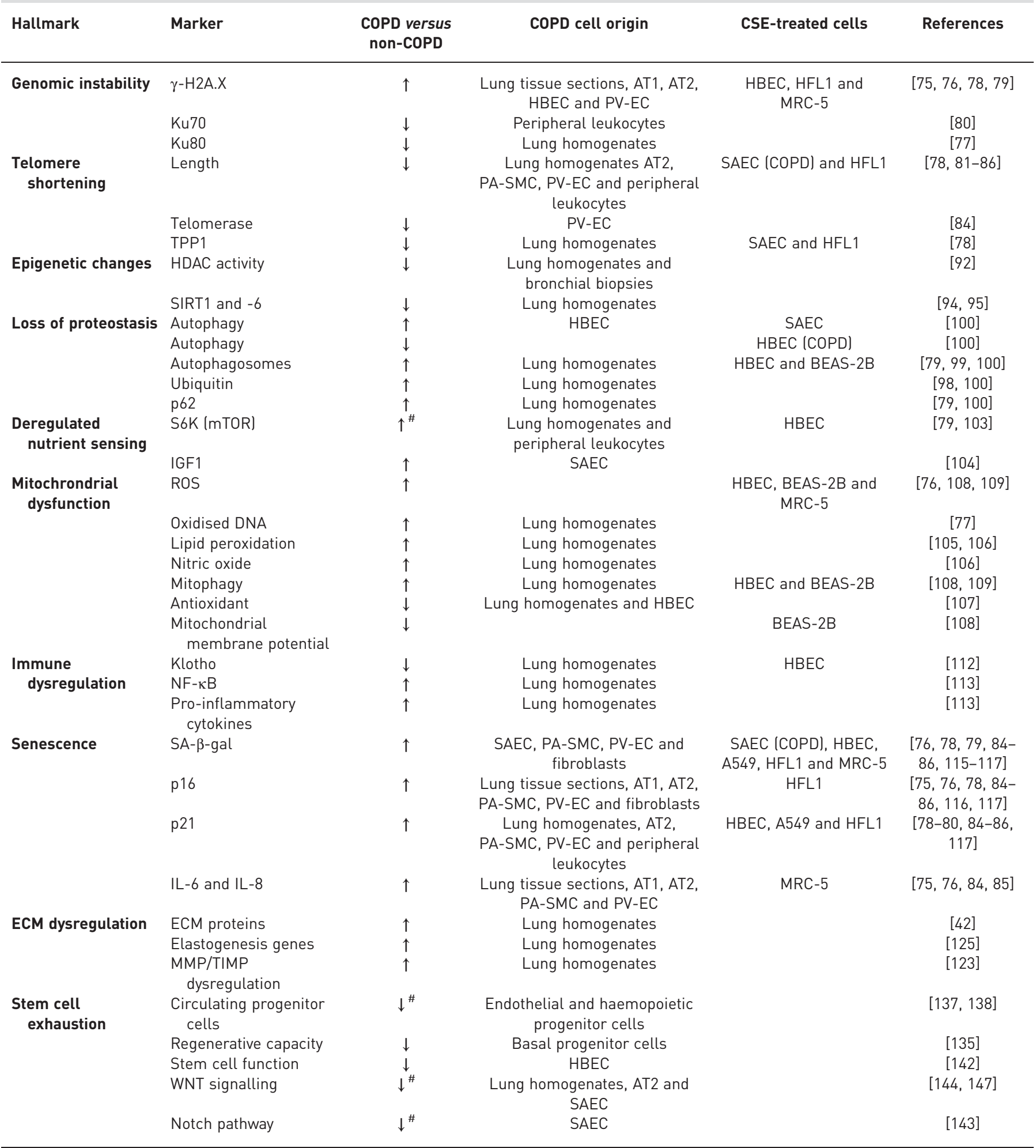

CSE: cigarette smoke extract; AT1: type I alveolar cells; AT2: type II alveolar cells; HBEC: human bronchial epithelial cells; PV-EC: pulmonary vascular endothelial cells; HFL1: fetal lung fibroblasts; MRC-5: fetal lung fibroblasts; TPP1: telomere protection protein 1; PA-SMC: pulmonary artery smooth muscle cells; SAEC: small airway epithelial cells; HDAC: histone deacetylase; SIRT: sirtuin; BEAS-2B: bronchial epithelial cell line (virus); mTOR: mechanistic target of rapamycin; IGF1: insulin-like growth factor 1; ROS: reactive oxygen species; SA- $\beta$-gal: senescence-associated- $\beta$-galactosidase; IL: interleukin; A549: alveolar basal epithelial cell line (carcinoma); ECM: extracellular matrix; MMP: matrix metalloproteinase; TIMP: tissue inhibitor of metalloproteinase. \#: mean age was significantly different between COPD and control group; for the other studies, information was not available or mean age was not different between groups. 
Ku70 is another DNA repair marker which is decreased in leukocytes derived from COPD patients, and its expression is negatively correlated with age [80].

\section{Telomere shortening}

Telomere shortening is an important inducer of senescence and a well-known phenomenon in ageing. Reduced telomere length in circulating leukocytes in COPD has been demonstrated in several studies [80-83], although data about telomere shortening in structural cells is still scarce.

Reduced telomere length has been demonstrated in pulmonary vascular endothelial cells and pulmonary artery smooth muscle cells derived from COPD patients when compared to cells derived from smoking controls [84, 85]. Tsuji et al. [86] used fluorescent in situ hybridisation to assess telomere length in alveolar type II and endothelial cells and demonstrated decreased telomere length in COPD patients when compared to nonsmoking controls, but not compared to smoking controls. A recent study from AHMAD et al. [78] assessed telomere length in lung tissue and reported an association with levels of telomere protection protein 1 (TPP1). Both telomere length and TTP1 levels were reduced in lung homogenates from COPD patients compared to nonsmoking controls, but not compared to smoking controls. This was further supported by decreased TTP1 levels and telomere length in CSE-treated airway epithelial cells and lung fibroblasts [78].

These findings of Tsuj et al. [86] and AHMAD et al. [78] suggest an association with smoking rather than being COPD specific, although given that most COPD patients are (ex-) smokers, this might be a contributing factor to disease risk and development.

\section{Epigenetic changes}

Epigenetic alterations caused by DNA methylation, histone modifications and noncoding RNAs are highly dynamic and influenced by ageing [87]. It has even been postulated that the DNA methylation status of particular CpG sites, also known as the "epigenetic clock", can be used in an algorithm to predict biological age $[88,89]$. However, as far as we know, this algorithm has not yet been applied to COPD patients to test if the biological age of COPD patients determined by their methylation status is indeed increased compared to controls, as would be expected. The majority of epigenome-wide methylation studies have been performed in whole blood, and few data are available on DNA methylation in whole lung tissue and lung tissue-specific cell types. Although it has been widely established that cigarette smoke affects DNA methylation [90] and that COPD is highly associated with cigarette smoke exposure, in a recent systematic review by MACHIN et al. [91], no consistent differences were found in DNA methylation in peripheral blood in association with COPD or lung function. Therefore, the role of DNA methylation in COPD and hence the role of age-associated differences in DNA methylation in COPD remain unclear.

Histone deacetylase (HDAC) enzymes can reduce the acetylation of histones, leading to enhanced expression of the inflammatory genes involved in the disease pathogenesis of COPD. It has been shown that HDAC activity is reduced in peripheral lung tissue, alveolar macrophages and bronchial biopsies of COPD patients compared to controls, and this activity is further associated with the disease severity of COPD in peripheral lung tissue [92]. The $\mathrm{NAD}^{+}$-dependent Class III protein deacetylases known as the Sirtuin family are frequently described as anti-ageing enzymes [93]. The fact that SIRT1 and -6 have been shown to be decreased in peripheral lung tissue (and SIRT1 also in serum) of COPD patients compared to controls suggests age-associated acetylation differences in COPD [94, 95]. BAKER et al. [94] postulate that the reduced expression of both Sirtuins is regulated by the microRNA MiR-34a, a small endogenous noncoding RNA, which appears to be increased in COPD patients compared to controls. Although the role of microRNAs in COPD has been extensively reviewed [96] the role of microRNAs in accelerated lung ageing is not extensively investigated and remains rather elusive [97].

\section{Metabolism}

Loss of proteostasis

Ageing cells are less able to maintain the homeostasis of proteins and contain more damaged proteins. In COPD lungs, proteostasis of cells is also decreased, resulting in accumulation of damaged proteins. Accumulation of ubiquitinated proteins and the de-ubiquitinating enzyme and aggregation marker, ubiquitin C-terminal hydrolase L1 (UCH-L1), is increased in the lung tissue of patients with severe COPD, and these levels negatively correlate with $\mathrm{FEV}_{1} \%$ predicted [98]. Furthermore, several autophagy markers are increased in COPD lung tissue, including p62, microtubule-associated proteins 1A/1B light chain 3B (LC3-II), autophagy-related 4 (Atg4), Atg5-Atg12 and Atg7 [79, 99].

Functional studies have shown that autophagy activity (LC3-II flux) is increased in bronchial epithelial cells of COPD patients, without further increase upon CSE treatment [100]. However, CSE treatment does increase the amount of autophagosomes in airway and bronchial epithelial cells [79, 99]. Inhibition of 
autophagy in bronchial epithelial cells results in accumulation of ubiquitinated protein and p62 [100]. Again, the anti-ageing molecule SIRT6 may also regulate autophagy, as SIRT6 overexpression and knockdown resulted in an increase and a decrease of autophagosomes, respectively [79].

\section{Deregulated nutrient sensing}

Nutrient sensing is a cell's ability to recognise and respond to fuel substrates such as glucose, and recent findings suggest that nutrient sensing is increased in COPD lungs. Caloric restriction is strongly associated with longevity, and this is possibly mediated by two main pathways involved in nutrient sensing: mechanistic target of rapamycin (mTOR) and insulin-like growth factor (IGF1) signalling [101, 102]. The activity of mTOR, an important protein kinase in cell metabolism and nutrient sensing, is increased in total lung tissue and leukocytes of COPD patients [103], as well as in CSE-treated bronchial epithelial cells [79]. In addition, SIRT6 is considered to attenuate the IGF1-mTOR pathway. The IGF1 pathway is important in cell growth and interacts with mTOR in the regulation of energy metabolism. Here, SIRT6 may also play a role, as overexpression and knockdown of SIRT6 resulted in decreased and increased IGF1-mTOR signalling, respectively [79]. Of interest, IGF1 protein levels were found to be increased in airway epithelial cells of patients with chronic bronchitis [104].

\section{Mitochondrial dysfunction}

With ageing, the function of the mitochondria decreases, which can lead to oxidative stress. Interestingly, increased levels of oxidative stress are observed in COPD lungs as well. In whole lung tissue of COPD patients, increased oxidative stress was found, as determined by ROS levels, oxidised DNA, lipid peroxidation and nitric oxide levels [77, 105, 106]. Moreover, lipid peroxidation correlated negatively with $\mathrm{FEV}_{1} \%$ pred [105]. In addition, gene expression and protein levels of the anti-oxidant nuclear factor, erythroid 2-like 2 (NRF2) were decreased in total lung tissue and bronchial epithelial cells of COPD patients [107], and NRF2 expression was positively correlated with airway obstruction (FEV1/FVC). Mitophagy, the degradation of mitochondria by autophagy, was increased in the total lung tissue of COPD patients [108].

Furthermore, CSE treatment of bronchial epithelial cells resulted in increased ROS levels and mitophagy and decreased mitochondrial potential $[108,109]$. In fibroblasts too, CSE treatment resulted in higher ROS levels [76].

\section{Cellular processes}

Immunosenescence and inflammaging

As described, ageing is associated with immunosenescence and inflammaging. These two factors underlie most age-associated diseases and are important during COPD development in aged individuals. Several recent studies have investigated how ageing might affect immune dysregulation in COPD. In a study from 2016, John-Schuster et al. [110] demonstrated that aged mice exposed to cigarette smoke are more susceptible to developing emphysema than younger mice. Aged animals had increased lung inflammation, with higher levels of inflammatory cells and mediators associated with lower repair. Two studies from 2015 observed that Klotho, an anti-ageing protein with anti-inflammatory properties, is reduced in alveolar macrophages [111] and airway epithelial cells of patients with COPD [112]. The reduction was associated with high levels of oxidative stress, inflammation and apoptosis [111, 112]. Furthermore, decreased expression of miR-125a and -b levels in COPD have been linked to inflammation and an impaired immune response. MiR-125a reduction resulted in NF- $\mathrm{BB}$ activation, with a classical induction of pro-inflammatory cytokines, while in parallel, low levels of miR-125a and -b suppress viral clearance [113]. These data underscore the potential of targeting inflammation and at the same time increasing resistance to infections in the aged individual with COPD.

\section{Cellular senescence}

Cellular senescence is a cell state in which normal cells stop dividing as a mechanism to prevent tumorigenesis and tissue damage. Senescent cells can be cleared by the immune system, but upon ageing the number of senescent cells increases in tissues. These cells can have detrimental effects, as they secrete several inflammatory factors and may disturb normal tissue homeostasis and repair due to the loss of proliferative capacity and normal physiological function [114]. Evidence is accumulating of increased cellular senescence in COPD lungs.

The percentage of senescence-associated $\beta$-galactosidase-positive cells has been found to be increased in multiple cell types in COPD patients, including airway epithelial cells, smooth muscle cells, endothelial cells and fibroblasts, as well as in CSE-treated alveolar and bronchial epithelial cells [76, 78, 79, 84, 85, $115,116]$. Another senescence marker, the cell cycle inhibitor p16, was found to be increased in total lung tissue, alveolar cells, airway epithelial cells, smooth muscle cells, endothelial cells and fibroblasts of COPD 
patients $[75,76,84-86,116]$. Similarly, the presence of p21, another cell cycle inhibitor, was increased in total lung tissue, alveolar cells, smooth muscle cells, endothelial cells and leukocytes of COPD patients [79, 80, 84-86]. p21 was also increased in CSE-treated bronchial epithelial cells and fibroblasts [78, 79, 117]. Moreover, the percentages of p16- and p21-positive cells were negatively correlated with FEV1 \% pred in alveolar type II and endothelial cells [86]. Levels of IL-6 and IL-8, two important cytokines that are secreted by senescent cells as part of the senescence-associated secretory phenotype, were increased in total lung tissue, alveolar cells, smooth muscle cells and endothelial cells of COPD patients as well as in CSE-treated fibroblasts [75, 76, 84, 85]. Although these cytokines can also be the result of ongoing inflammation in COPD, these observations cannot be directly related to an increase in cellular senescence.

\section{ECM dysregulation}

Age-related changes in the lung can also be observed at extracellular levels. Comparable to the ageing lung $[118,119]$ the ECM is altered in COPD [120]. The main alterations in COPD include increases of several ECM proteins, such as collagens, fibronectin and laminin [42], changes in the structural organisation of collagen, with more disorganised collagen fibres [121], and also a reduction in elastic fibres [122]. An important contributing factor to these ECM changes is the imbalance between proteases, such as matrix metalloproteinase 12 (MMP12) and neutrophil elastase, and anti-proteases, like $\alpha_{1}$-antitrypsin and tissue inhibitor of metalloproteinase (TIMP) 1-4, as reviewed by NAVRATILOVA et al. [123].

Elastin degradation plays an important role in the pathogenesis of COPD. Elastin fragments alone are known to induce inflammation, leading to destruction of lung tissue [124]. It was previously thought that in COPD the lung loses its ability to repair; however, it has become increasingly more evident that there may be aberrant attempts at repair. A number of genes encoding for elastogenesis components, such as fibulin-5 (FBLN5), microfibril-associated protein 4 (MFAP4), latent transforming growth factor binding protein 2 (LTBP2) and elastin (ELN) itself were identified in a large COPD patient cohort to be more highly expressed [125]. Whether these components are beneficial or further drive disease pathogenesis remains unclear, as extracellular proteins have the potential to interfere with different cellular pathways $[126,127]$.

Another interesting observation in COPD is the change in lung fibroblast responses in vitro. Lung fibroblasts are the main cells involved in ECM homeostasis and repair in the lung, and several studies have shown differences in terms of ECM production when comparing COPD fibroblasts to those derived from non-COPD controls [128-131], suggesting a disturbed or abnormal repair capacity of these cells.

\section{Stem cell exhaustion}

Adult lung tissue is thought to reside in a quiescent state. Upon injury, (stem) cells can be activated and are able to proliferate and (trans)differentiate into other cell types, according to their plasticity [132]. Indeed, the lung harbours different cell populations including stem cells, which are responsible for its unique homeostatic capacity to ensure gas exchange [133, 134]. Airway basal cells represent a well-characterised stem cell population located in the trachea and bronchi. These cells have the ability to self-renew and give rise to secretory, ciliated and neuroendocrine cells [135]. In the distal lung, alveolar type II cells [136] have been shown to be able to replenish lost alveolar type II cells and transdifferentiate to alveolar type I cells, thus ensuring proper gas exchange [132, 133]. It is most likely that other progenitor or stem cell subpopulations exist, as indicated by several studies in mouse tissue over recent years; however, the existence of these cells in human tissue, and their relevance for tissue injury and potentially impaired repair, remain unclear.

COPD has been associated with reduced numbers and dysfunction of circulating progenitor cells [137, 138]. Cigarette smoke, a major risk factor for COPD, has been shown to reduce the repair potential of endothelial progenitor cells [139] and bone marrow mesenchymal stem cells by interfering with cell homing and proliferation capacities [140]. Thus, stem cell exhaustion might contribute to COPD pathogenesis by reducing the endogenous renewal and repair capacity of the lung by local as well as recruited cells. Stem cell niches fail to respond effectively to additional demands for cell turnover; moreover, deranged metabolic signalling and premature senescence might occur [141]. In line with this, reduced regenerative capacity of basal progenitor cells has been reported in COPD [135]. In addition, in a different study, an abnormal population of $\mathrm{TRP} 3^{+} \mathrm{KRT}^{+} \mathrm{KRT} 14^{+}$basal cells was identified in regions of hyperplasia from sections of COPD human airways [142], suggesting abnormal stem cell function. Developmental pathways, such as WNT, Sonic Hedgehog and Notch, are important susceptibility factors for COPD [143-145] and are associated with the regulation of different stem cell functions [146]. Canonical WNT signalling, which relies on the stabilisation of $\beta$-catenin for transcriptional activation, is decreased in COPD [144, 147, 148]. Notably, pharmaceutical activation of the pathway led to an increase in surfactant protein $\mathrm{C}$ production and secretion, along with increased alveolar type I cell marker 
expression in COPD lung tissue ex vivo, suggesting that the initiation of stem-cell-mediated repair in the COPD lung is possible [149].

\section{Evidence for ageing hallmarks and abnormal tissue repair in COPD}

Increased levels of DNA damage and decreased levels of DNA repair markers have been demonstrated in COPD, in particular in the alveolar compartment. Although the data are derived from a limited number of studies, they do indicate a role for these ageing markers in COPD, in particular in relation to emphysema development, with increased alveolar wall destruction and lack of repair.

Another key hallmark in ageing is telomere shortening. Information on telomere length in structural cells is mostly lacking, so it is difficult to speculate on a role of telomere shorting in relation to tissue repair and remodelling in COPD. However, reduced TPP1 levels in relation to smoking in lung tissue and structural cells do suggest an effect of smoking. Whether this also relates to smoking-induced COPD remains to be elucidated.

Regarding epigenetic changes in COPD, solid data on DNA methylation are lacking, so it is not yet possible to infer a role for DNA methylation in abnormal tissue repair in COPD. Several studies have indicated involvement of histone modification (HDAC and Sirtuins) and microRNAs in COPD and it is of great interest to further evaluate if and how these changes contribute to accelerated lung ageing and abnormal tissue repair in COPD.

With respect to the metabolic changes in COPD, increased autophagy and accumulation of damaged proteins reflects ongoing tissue damage and high protein turnover in COPD. Whether this is the cause or consequence (or both) of the abnormal repair response is currently unclear. Similarly, disturbed nutrient sensing (IGF1-mTOR) and the oxidant-antioxidant imbalance indicate that, as with normal ageing, cell homeostasis is disturbed, which makes the cells vulnerable to disease. However, whether and how this contributes to abnormal repair should be evaluated by further studies.

Of all the ageing hallmarks in COPD, changes in cellular processes are probably the best studied. Multiple studies have shown increased cellular senescence and changes in ECM regulation in COPD, in particular in structural cells, including epithelial cells, smooth muscle cells and fibroblasts. The latter are of particular interest, as fibroblasts are the main regulators of tissue repair in the lung, and changes in these cells possibly underlie the abnormal tissue repair responses in COPD. Together with the reduced numbers, dysfunction and regenerative capacity of progenitor cells in COPD, these age-related cellular changes may very well explain the disturbed repair and remodelling capacity of COPD lungs, in both the alveolar and airway compartments.

\section{Implications for treatment}

COPD exacerbations are of major concern in the elderly, as they are highly susceptible to infections. Due to a dampened immune system, vaccination is not considered a successful preventive measure [150]. Having this in mind, strategies that boost the immune system have been proposed for lung disease treatment. One of the strategies is interference with the gut microbiota [151]. The local microbiota influences immunity at distal sites and organs. Bifidobacterium breve and Lactobacillus rhamnosus have been shown to reduce inflammatory responses in macrophages that are exposed to CSE in vitro [152]. Another potential future therapy is based on the application and usage of stem cells. In 2013, bone-marrow-derived mesenchymal stem cells (MSCs) were first transplanted to patients, with no adverse effects observed in older patients [153]. More recently, an immunomodulatory mechanism has been associated with MSCs treatment, which decreased lung inflammation and improved lung function [154]. Furthermore, as aforementioned, pharmaceutical activation of the WNT pathway has shown promising effects ex vivo and suggests opportunities to induce endogenous stem-cell-mediated repair in COPD [149].

Although stem cell therapies hold promise as future therapeutic options, more regulations and clinical trials on the matter are needed to optimise therapeutic schemes, dosages, infusion rates and further identify possible risk groups and specific adverse effects [155]. Ultimately, understanding the molecular biology of ageing in the lung is crucial for finding new ways of managing COPD in older but also younger (severe early-onset COPD) patients.

\section{Summary and conclusions}

As summarised in this review, the main ageing hallmarks are present in COPD, and this supports the hypothesis that (abnormal) ageing contributes to COPD development. With respect to the role of abnormal ageing in tissue repair in COPD, the strongest indications come from cellular changes, i.e. increased cellular senescence, ECM dysregulation and stem cell exhaustion. Yet, to be able to answer our question of whether accelerated or abnormal ageing is causally contributing to COPD pathogenesis and in 
particular impaired tissue repair, we need to integrate all findings and assess how age-related changes affect ECM homeostasis and tissue repair in the lung. Ideally this should not be restricted to single-cell culture models with primary lung cells, but should also involve more complex co-culture and organoid models, lung tissue slices and/or lab-on-a-chip approaches. An important aspect that needs to be taken into account is age-matching between the control and COPD groups. Indeed, for some studies discussed in this review, the mean age was significantly different in the control and COPD groups (as indicated in table 1). This may come as a challenge in distinguishing the effects that are related to age and those that are related to COPD. Finally, translation and comparison to in vivo models and to what happens in the lungs of actual COPD patients are important for the identification of potential new therapeutic approaches. Evaluation in well-defined clinical samples is crucial to understand the clinical implications and potential benefit for COPD patients. This information may also guide us towards novel approaches aiming to stop or at least slow down accelerated lung ageing in COPD. These could provide a future perspective for the most vulnerable group of COPD patients, those with severe early-onset-COPD, who suffer from the highest disease burden and lack adequate treatment.

\section{References}

Ito K, Barnes PJ. COPD as a disease of accelerated lung aging. Chest 2009; 135: 173-180.

World Health Organization. Noncommunicable Diseases. Available from: www.who.int/mediacentre/factsheets/ fs355/en/ Date last updated: June 2017.

3 Mercado N, Ito K, Barnes PJ. Accelerated ageing of the lung in COPD: new concepts. Thorax 2015; 70: 482-489.

4 Rojas M, Meiners S, Le Saux CJ, eds. Molecular Aspects of Aging: Understanding Lung Aging. Hoboken, John Wiley \& Sons Inc., 2014.

$5 \quad$ Miller MR. Structural and physiological age-associated changes in aging lungs. Semin Respir Crit Care Med 2010; 31: 521-527.

6 Thurlbeck WM, Angus GE. Growth and aging of the normal human lung. Chest 1975; 67: Suppl. 2, 3S-6S.

7 Lamb D, Gillooly M, Farrow AS. Microscopic emphysema and its variations with age, smoking, and site within the lungs. Ann NY Acad Sci 1991; 624: 339-340.

8 Gillooly M, Lamb D. Airspace size in lungs of lifelong non-smokers: effect of age and sex. Thorax 1993; 48: 39-43.

9 Janssens JP, Pache JC, Nicod LP. Physiological changes in respiratory function associated with ageing. Eur Respir J 1999; 13: 197-205.

10 MacNee W. Is chronic obstructive pulmonary disease an accelerated aging disease? Ann Am Thorac Soc 2016; 13: Suppl. 5, S429-S437.

11 López-Otín C, Blasco MA, Partridge L, et al. The hallmarks of aging. Cell 2013; 153: 1194-1217.

12 Franceschi C, Bonafè M, Valensin S, et al. Inflamm-aging. An evolutionary perspective on immunosenescence. Ann NY Acad Sci 2000; 908: 244-254.

13 Boe DM, Boule LA, Kovacs EJ. Innate immune responses in the ageing lung. Clin Exp Immunol 2017; 187: $16-25$.

14 De Martinis M, Franceschi C, Monti D, et al. Inflamm-ageing and lifelong antigenic load as major determinants of ageing rate and longevity. FEBS Lett 2005; 579: 2035-2039.

15 Lowery EM, Brubaker AL, Kuhlmann E, et al. The aging lung. Clin Interv Aging 2013; 8: 1489-1496.

16 Bailey KL, Bonasera SJ, Wilderdyke M, et al. Aging causes a slowing in ciliary beat frequency, mediated by PKCepsilon. Am J Physiol Lung Cell Mol Physiol 2014; 306: L584-L589.

17 Hogg JC, Timens W. The pathology of chronic obstructive pulmonary disease. Annu Rev Pathol 2009; 4: 435-459.

18 Willemse BW, Ten Hacken NH, Rutgers B, et al. Association of current smoking with airway inflammation in chronic obstructive pulmonary disease and asymptomatic smokers. Respir Res 2005; 6: 38.

19 Hogg JC, Timens W. The pathology of chronic obstructive pulmonary disease. Annu Rev Pathol 2009; 4: 435-459.

20 Saetta M, Turato G, Timens W, et al. Pathology of chronic obstructive pulmonary disease. In: Siafakas NM, ed. Management of Chronic Obstructive Pulmonary Disease (ERS Monograph). Sheffield, European Respiratory Society, 2006; pp. 159-176.

21 Rutgers SR, Postma DS, Ten Hacken NH, et al. Ongoing airway inflammation in patients with COPD who do not currently smoke. Thorax 2000; 55: 12-18.

22 Willemse BW, Ten Hacken NH, Rutgers B, et al. Effect of 1-year smoking cessation on airway inflammation in COPD and asymptomatic smokers. Eur Respir J 2005; 26: 835-845.

23 Lapperre TS, Postma DS, Gosman MM, et al. Relation between duration of smoking cessation and bronchial inflammation in COPD. Thorax 2006; 61: 115-121.

24 Postma DS, Timens W. Remodeling in asthma and chronic obstructive pulmonary disease. Proc Am Thorac Soc 2006; 3: 434-439.

25 Berg K, Wright JL. The pathology of chronic obstructive pulmonary disease: progress in the 20th and 21st centuries. Arch Pathol Lab Med 2016; 140: 1423-1428.

26 O'Shaughnessy TC, Ansari TW, Barnes NC, et al. Inflammation in bronchial biopsies of subjects with chronic bronchitis: inverse relationship of CD8+ T lymphocytes with FEV1. Am J Respir Crit Care Med 1997; 155: 852-857.

27 Saetta M, Di Stefano A, Turato G, et al. CD8+ T-lymphocytes in peripheral airways of smokers with chronic obstructive pulmonary disease. Am J Respir Crit Care Med 1998; 157: 822-826.

28 Zhu J, Qiu YS, Majumdar S, et al. Exacerbations of bronchitis: bronchial eosinophilia and gene expression for interleukin-4, interleukin-5, and eosinophil chemoattractants. Am J Respir Crit Care Med 2001; 164: 109-116.

29 Gosman MM, Willemse BW, Jansen DF, et al. Increased number of B-cells in bronchial biopsies in COPD. Eur Respir J 2006; 27: 60-64. 
Hogg JC, Chu F, Utokaparch S, et al. The nature of small-airway obstruction in chronic obstructive pulmonary disease. N Engl J Med 2004; 350: 2645-2653.

van der Strate BW, Postma DS, Brandsma CA, et al. Cigarette smoke-induced emphysema: a role for the B cell? Am J Respir Crit Care Med 2006; 173: 751-758.

Brusselle GG, Demoor T, Bracke KR, et al. Lymphoid follicles in (very) severe COPD: beneficial or harmful? Eur Respir J 2009; 34: 219-230.

Brandsma CA, Hylkema MN, van der Strate BW, et al. Heme oxygenase-1 prevents smoke induced B-cell infiltrates: a role for regulatory T cells? Respir Res 2008; 9: 17.

Brandsma CA, Kerstjens HA, Geerlings M, et al. The search for autoantibodies against elastin, collagen and decorin in COPD. Eur Respir J 2011; 37: 1289-1292.

Brandsma CA, Kerstjens HA, van Geffen WH, et al. Differential switching to IgG and IgA in active smoking COPD patients and healthy controls. Eur Respir J 2012; 40: 313-321.

Lee SH, Goswami S, Grudo A, et al. Antielastin autoimmunity in tobacco smoking-induced emphysema. Nat Med 2007; 13: 567-569.

Greene CM, Low TB, O’Neill SJ, et al. Anti-proline-glycine-proline or antielastin autoantibodies are not evident in chronic inflammatory lung disease. Am J Respir Crit Care Med 2010; 181: 31-35.

Jeffery PK. Comparison of the structural and inflammatory features of COPD and asthma. Giles F. Filley Lecture. Chest 2000; 117: 251S-260S.

Lapperre TS, Sont JK, van Schadewijk A, et al. Smoking cessation and bronchial epithelial remodelling in COPD: a cross-sectional study. Respir Res 2007; 8: 85.

Saetta M, Turato G, Maestrelli P, et al. Cellular and structural bases of chronic obstructive pulmonary disease Am J Respir Crit Care Med 2001; 163: 1304-1309.

Jeffery PK. Morphology of the airway wall in asthma and in chronic obstructive pulmonary disease. Am Rev Respir Dis 1991; 143: 1152-1158.

Kranenburg AR, Willems-Widyastuti A, Moori WJ, et al. Enhanced bronchial expression of extracellular matrix proteins in chronic obstructive pulmonary disease. Am J Clin Pathol 2006; 126: 725-735.

Liesker JJ, Ten Hacken NH, Zeinstra-Smith M, et al. Reticular basement membrane in asthma and COPD: similar thickness, yet different composition. Int J Chron Obstruct Pulmon Dis 2009; 4: 127-135.

Kunz LI, Strebus J, Budulac SE, et al. Inhaled steroids modulate extracellular matrix composition in bronchial biopsies of COPD patients: a randomized, controlled trial. PLoS One 2013; 8: e63430.

van Straaten JF, Coers W, Noordhoek JA, et al. Proteoglycan changes in the extracellular matrix of lung tissue from patients with pulmonary emphysema. Mod Pathol 1999; 12: 697-705.

Zandvoort A, Postma DS, Jonker MR, et al. Altered expression of the Smad signalling pathway: implications for COPD pathogenesis. Eur Respir J 2006; 28: 533-541.

De Boer WI, van Schadewijk A, Sont JK, et al. Transforming growth factor $\beta 1$ and recruitment of macrophages and mast cells in airways in chronic obstructive pulmonary disease. Am J Respir Crit Care Med 1998; 158: 1951-1957.

van der Geld YM, Van Straaten JFM, Postma DS, et al. Role of proteoglycans in development and pathogenesis of emphysema. In: Garg HG, Roughley PJ, Hales CA, eds. Proteoglycans in Lung Disease. New York, Marcel Dekker, 2002; pp. 241-267.

Gubbiotti MA, Vallet SD, Ricard-Blum S, et al. Decorin interacting network: a comprehensive analysis of decorin-binding partners and their versatile functions. Matrix Biol 2016; 55: 7-21.

McDonough JE, Yuan R, Suzuki M, et al. Small-airway obstruction and emphysema in chronic obstructive pulmonary disease. $N$ Engl J Med 2011; 365: 1567-1575.

Hogg JC, McDonough JE, Suzuki M. Small airway obstruction in COPD: new insights based on micro-CT imaging and MRI imaging. Chest 2013; 143: 1436-1443.

Barnes PJ. Chronic obstructive pulmonary disease. N Engl J Med 2000; 343: 269-280. S17-S20.

Airway inflammation in chronic obstructive pulmonary disease. Am J Respir Crit Care Med 1999; 160

Saetta M, Baraldo S, Corbino L, et al. CD8+ve cells in the lungs of smokers with chronic obstructive pulmonary disease. Am J Respir Crit Care Med 1999; 160: 711-717.

Eidelman D, Saetta MP, Ghezzo H, et al. Cellularity of the alveolar walls in smokers and its relation to alveolar destruction. Functional implications. Am Rev Respir Dis 1990; 141: 1547-1552.

Demedts IK, Demoor T, Bracke KR, et al. Role of apoptosis in the pathogenesis of COPD and pulmonary emphysema. Respir Res 2006; 7: 53.

Voelkel NF, Cool CD. Pulmonary vascular involvement in chronic obstructive pulmonary disease. Eur Respir J 2003; 22: Suppl. 46, 28s-32s.

Wright JL, Petty T, Thurlbeck WM. Analysis of the structure of the muscular pulmonary arteries in patients with pulmonary hypertension and COPD: National Institutes of Health nocturnal oxygen therapy trial. Lung 1992; 170: 109-124.

Wright JL, Levy RD, Churg A. Pulmonary hypertension in chronic obstructive pulmonary disease: current theories of pathogenesis and their implications for treatment. Thorax 2005; 60: 605-609.

Barberà JA, Riverola A, Roca J, et al. Pulmonary vascular abnormalities and ventilation-perfusion relationships in mild chronic obstructive pulmonary disease. Am J Respir Crit Care Med 1994; 149: 423-429.

Peinado VI, Pizarro S, Barberà JA. Pulmonary vascular involvement in COPD. Chest 2008; 134: 808-814.

Budhiraja R, Tuder RM, Hassoun PM. Endothelial dysfunction in pulmonary hypertension. Circulation 2004; 109: 159-165.

Verbeken EK, Cauberghs M, Mertens I, et al. The senile lung. Comparison with normal and emphysematous lungs. 1. Structural aspects. Chest 1992; 101: 793-799.

lungs. 2. Functional aspects. Chest 1992; 101: 800-809.

Kirkwood TB. Evolution of ageing. Nature 1977; 270: 301-304.

Kirkwood TB. Understanding the odd science of aging. Cell 2005; 120: 437-447. 
Hurst JR, Vestbo J, Anzueto A, et al. Susceptibility to exacerbation in chronic obstructive pulmonary disease N Engl J Med 2010; 363: 1128-1138.

Miravitlles M, Calle M, Soler-Cataluña JJ. Clinical phenotypes of COPD: identification, definition and implications for guidelines. Arch Bronconeumol 2012; 48: 86-98.

Silverman EK, Chapman HA, Drazen JM, et al. Genetic epidemiology of severe, early-onset chronic obstructive pulmonary disease. Risk to relatives for airflow obstruction and chronic bronchitis. Am J Respir Crit Care Med 1998; 157: 1770-1778.

Bafadhel M, McKenna S, Terry S, et al. Acute exacerbations of chronic obstructive pulmonary disease: identification of biologic clusters and their biomarkers. Am J Respir Crit Care Med 2011; 184: 662-671.

Santos S, Marin A, Serra-Batlles J, et al. Treatment of patients with COPD and recurrent exacerbations: the role of infection and inflammation. Int J Chron Obstruct Pulmon Dis 2016; 11: 515-525.

Montserrat-Capdevila J, Godoy P, Marsal JR, et al. Risk of exacerbation in chronic obstructive pulmonary disease: a primary care retrospective cohort study. BMC Fam Pract 2015; 16: 173.

Hunter LC, Lee RJ, Butcher I, et al. Patient characteristics associated with risk of first hospital admission and readmission for acute exacerbation of chronic obstructive pulmonary disease (COPD) following primary care COPD diagnosis: a cohort study using linked electronic patient records. BMJ Open 2016; 6: e009121.

Meiners S, Eickelberg O, Königshoff M. Hallmarks of the ageing lung. Eur Respir J 2015; 45: 807-827.

Aoshiba K, Zhou F, Tsuji T, et al. DNA damage as a molecular link in the pathogenesis of COPD in smokers. Eur Respir J 2012; 39: 1368-1376.

Birch J, Anderson RK, Correia-Melo C, et al. DNA damage response at telomeres contributes to lung aging and chronic obstructive pulmonary disease. Am J Physiol Lung Cell Mol Physiol 2015; 309: L1124-L1137.

Caramori G, Adcock IM, Casolari P, et al. Unbalanced oxidant-induced DNA damage and repair in COPD: a link towards lung cancer. Thorax 2011; 66: 521-527.

Ahmad T, Sundar IK, Tormos AM, et al. Shelterin telomere protection protein 1 reduction causes telomere attrition and cellular senescence via sirtuin 1 deacetylase in chronic obstructive pulmonary disease. Am J Respir Cell Mol Biol 2017; 56: 38-49.

Takasaka N, Araya J, Hara H, et al. Autophagy induction by SIRT6 through attenuation of insulin-like growth factor signaling is involved in the regulation of human bronchial epithelial cell senescence. J Immunol 2014; 192: 958-968.

Rutten EP, Gopal P, Wouters EF, et al. Various mechanistic pathways representing the aging process are altered in COPD. Chest 2016; 149: 53-61.

Savale L, Chaouat A, Bastuji-Garin S, et al. Shortened telomeres in circulating leukocytes of patients with chronic obstructive pulmonary disease. Am J Respir Crit Care Med 2009; 179: 566-571.

Houben JM, Mercken EM, Ketelslegers HB, et al. Telomere shortening in chronic obstructive pulmonary disease. Respir Med 2009; 103: 230-236.

Lee J, Sandford AJ, Connett JE, et al. The relationship between telomere length and mortality in chronic obstructive pulmonary disease (COPD). PLoS One 2012; 7: e35567.

Amsellem V, Gary-Bobo G, Marcos E, et al. Telomere dysfunction causes sustained inflammation in chronic obstructive pulmonary disease. Am J Respir Crit Care Med 2011; 184: 1358-1366.

Noureddine H, Gary-Bobo G, Alifano M, et al. Pulmonary artery smooth muscle cell senescence is a pathogenic mechanism for pulmonary hypertension in chronic lung disease. Circ Res 2011; 109: 543-553.

Tsuji T, Aoshiba K, Nagai A. Alveolar cell senescence in patients with pulmonary emphysema. Am J Respir Crit Care Med 2006; 174: 886-893.

Yang IV, Schwartz DA. Epigenetic control of gene expression in the lung. Am J Respir Crit Care Med 2011; 183 1295-1301.

Horvath S. DNA methylation age of human tissues and cell types. Genome Biol 2013; 14: R115.

Hannum G, Guinney J, Zhao L, et al. Genome-wide methylation profiles reveal quantitative views of human aging rates. Mol Cell 2013; 49: 359-367.

Gao X, Jia M, Zhang Y, et al. DNA methylation changes of whole blood cells in response to active smoking exposure in adults: a systematic review of DNA methylation studies. Clin Epigenetics 2015; 7: 113.

Machin M, Amaral AF, Wielscher M, et al. Systematic review of lung function and COPD with peripheral blood DNA methylation in population based studies. BMC Pulm Med 2017; 17: 54.

Ito K, Ito M, Elliott WM, et al. Decreased histone deacetylase activity in chronic obstructive pulmonary disease N Engl J Med 2005; 352: 1967-1976.

Michan S, Sinclair D. Sirtuins in mammals: insights into their biological function. Biochem J 2007; 404: 1-13.

Baker JR, Vuppusetty C, Colley T, et al. Oxidative stress dependent microRNA-34a activation via PI3K $\alpha$ reduces the expression of sirtuin-1 and sirtuin-6 in epithelial cells. Sci Rep 2016; 6: 35871.

Yanagisawa S, Papaioannou AI, Papaporfyriou A, et al. Decreased serum sirtuin-1 in COPD. Chest 2017; 152 343-352.

Osei ET, Florez-Sampedro L, Timens W, et al. Unravelling the complexity of COPD by microRNAs: it's a small world after all. Eur Respir J 2015; 46: 807-818.

Christenson SA, Brandsma CA, Campbell JD, et al. MiR-638 regulates gene expression networks associated with emphysematous lung destruction. Genome Med 2013; 5: 114.

Min T, Bodas M, Mazur S, et al. Critical role of proteostasis-imbalance in pathogenesis of COPD and severe emphysema. J Mol Med 2011; 89: 577-593.

Chen ZH, Kim HP, Sciurba FC, et al. Egr-1 regulates autophagy in cigarette smoke-induced chronic obstructive pulmonary disease. PLoS One 2008; 3: e3316.

Fujii S, Hara H, Araya J, et al. Insufficient autophagy promotes bronchial epithelial cell senescence in chronic obstructive pulmonary disease. Oncoimmunology 2012; 1: 630-641.

Mathew R, Pal Bhadra M, Bhadra U. Insulin/insulin-like growth factor-1 signalling (IIS) based regulation of lifespan across species. Biogerontology 2017; 18: 35-53.

Carmona JJ, Michan S. Biology of healthy aging and longevity. Rev Invest Clin 2016; 68: 7-16.

Mitani A, Ito K, Vuppusetty C, et al. Restoration of corticosteroid sensitivity in chronic obstructive pulmonary disease by inhibition of mammalian target of rapamycin. Am J Respir Crit Care Med 2016; 193: 143-153. 
Chand HS, Harris JF, Mebratu Y, et al. Intracellular insulin-like growth factor-1 induces Bcl-2 expression in airway epithelial cells. J Immunol 2012; 188: 4581-4589.

Rahman I, van Schadewijk AA, Crowther AJ, et al. 4-Hydroxy-2-nonenal, a specific lipid peroxidation product, is elevated in lungs of patients with chronic obstructive pulmonary disease. Am J Respir Crit Care Med 2002; 166: 490-495.

Rajendrasozhan S, Yang SR, Kinnula VL, et al. SIRT1, an antiinflammatory and antiaging protein, is decreased in lungs of patients with chronic obstructive pulmonary disease. Am J Respir Crit Care Med 2008; 177: 861-870.

Suzuki M, Betsuyaku T, Ito Y, et al. Down-regulated NF-E2-related factor 2 in pulmonary macrophages of aged smokers and patients with chronic obstructive pulmonary disease. Am J Respir Cell Mol Biol 2008; 39: 673-682.

Mizumura K, Cloonan SM, Nakahira K, et al. Mitophagy-dependent necroptosis contributes to the pathogenesis of COPD. J Clin Invest 2014; 124: 3987-4003.

Hara H, Araya J, Ito S, et al. Mitochondrial fragmentation in cigarette smoke-induced bronchial epithelial cell senescence. Am J Physiol Lung Cell Mol Physiol 2013; 305: L737-L746.

John-Schuster G, Günter S, Hager K, et al. Inflammaging increases susceptibility to cigarette smoke-induced COPD. Oncotarget 2016; 7: 30068-30083.

Li L, Wang Y, Gao W, et al. Klotho reduction in alveolar macrophages contributes to cigarette smoke extract-induced inflammation in chronic obstructive pulmonary disease. J Biol Chem 2015; 290: 27890-27900.

Gao W, Yuan C, Zhang J, et al. Klotho expression is reduced in COPD airway epithelial cells: effects on inflammation and oxidant injury. Clin Sci 2015; 129: 1011-1023.

Hsu AC, Dua K, Starkey MR, et al. MicroRNA-125a and -b inhibit A20 and MAVS to promote inflammation and impair antiviral response in COPD. JCI Insight 2017; 2: e90443.

Sci 2014; 71: 4373-4386.

Müller KC, Welker L, Paasch K, et al. Lung fibroblasts from patients with emphysema show markers of senescence in vitro. Respir Res 2006; 7: 32.

Hashimoto Y, Sugiura H, Togo S, et al. 27-Hydroxycholesterol accelerates cellular senescence in human lung resident cells. Am J Physiol Lung Cell Mol Physiol 2016; 310: L1028-L1041.

Nyunoya T, Monick MM, Klingelhutz A, et al. Cigarette smoke induces cellular senescence. Am J Respir Cell Mol Biol 2006; 35: 681-688.

D'Errico A, Scarani P, Colosimo E, et al. Changes in the alveolar connective tissue of the ageing lung. An immunohistochemical study. Virchows Arch A Pathol Anat Histopathol 1989; 415: 137-144.

Frette C, Jacob MP, Wei SM, et al. Relationship of serum elastin peptide level to single breath transfer factor for carbon monoxide in French coal miners. Thorax 1997; 52: 1045-1050.

Jones RL, Noble PB, Elliot JG, et al. Airway remodelling in COPD: It's not asthma! Respirology 2016; 21: 1347-1356.

Tjin G, Xu P, Kable SH, et al. Quantification of collagen I in airway tissues using second harmonic generation. J Biomed Opt 2014; 19: 36005.

Black PN, Ching PS, Beaumont B, et al. Changes in elastic fibres in the small airways and alveoli in COPD. Eur Respir J 2008; 31: 998-1004.

Navratilova Z, Kolek V, Petrek M. Matrix metalloproteinases and their inhibitors in chronic obstructive pulmonary disease. Arch Immunol Ther Exp 2016; 64: 177-193.

Houghton AM, Quintero PA, Perkins DL, et al. Elastin fragments drive disease progression in a murine model of emphysema. J Clin Invest 2006; 116: 753-759.

Brandsma CA, van den Berge M, Postma DS, et al. A large lung gene expression study identifying fibulin-5 as a novel player in tissue repair in COPD. Thorax 2015; 70: 21-32.

Wagner DE, Bonenfant NR, Parsons CS, et al. Comparative decellularization and recellularization of norma versus emphysematous human lungs. Biomaterials 2014; 35: 3281-3297. 15022-15034.

Krimmer DI, Burgess JK, Wooi TK, et al. Matrix proteins from smoke-exposed fibroblasts are pro-proliferative. Am J Respir Cell Mol Biol 2012; 46: 34-39.

Hallgren O, Nihlberg K, Dahlback M, et al. Altered fibroblast proteoglycan production in COPD. Respir Res 2010; 11: 55 .

Zandvoort A, Postma DS, Jonker MR, et al. Smad gene expression in pulmonary fibroblasts: indications for defective ECM repair in COPD. Respir Res 2008; 9: 83.

Larsson-Callerfelt AK, Hallgren O, Andersson-Sjoland A, et al. Defective alterations in the collagen network to prostacyclin in COPD lung fibroblasts. Respir Res 2013; 14: 21.

Crosby LM, Waters CM. Epithelial repair mechanisms in the lung. Am J Physiol Lung Cell Mol Physiol 2010; 298: L715-L731.

Kotton DN, Morrisey EE. Lung regeneration: mechanisms, applications and emerging stem cell populations. Nat Med 2014; 20: 822-832.

Miller AJ, Spence JR. In vitro models to study human lung development, disease and homeostasis. Physiology 2017; 32: 246-260.

Staudt MR, Buro-Auriemma LJ, Walters MS, et al. Airway basal stem/progenitor cells have diminished capacity to regenerate airway epithelium in chronic obstructive pulmonary disease. Am J Respir Crit Care Med 2014; 190: 955-958.

Barkauskas CE, Cronce MJ, Rackley CR, et al. Type 2 alveolar cells are stem cells in adult lung. J Clin Invest 2013; 123: 3025-3036.

Fadini GP, Schiavon M, Cantini M, et al. Circulating progenitor cells are reduced in patients with severe lung disease. Stem Cells 2006; 24: 1806-1813.

Palange P, Testa U, Huertas A, et al. Circulating haemopoietic and endothelial progenitor cells are decreased in COPD. Eur Respir J 2006; 27: 529-541. 

obstructive pulmonary disease patients due to increased DNA damage and senescence. Stem Cells 2013; 31: 2813-2826.

140 Tura-Ceide O, Lobo B, Paul T, et al. Cigarette smoke challenges bone marrow mesenchymal stem cell capacities in guinea pig. Respir Res 2017; 18: 50.

141 Boyette LB, Tuan RS. Adult stem cells and diseases of aging. J Clin Med 2014; 3: 88-134.

142 Rock JR, Randell SH, Hogan BL. Airway basal stem cells: a perspective on their roles in epithelial homeostasis and remodeling. Dis Model Mech 2010; 3: 545-556.

143 Tilley AE, Harvey BG, Heguy A, et al. Down-regulation of the notch pathway in human airway epithelium in association with smoking and chronic obstructive pulmonary disease. Am J Respir Crit Care Med 2009; 179: 457-466.

144 Kneidinger N, Yildirim AO, Callegari J, et al. Activation of the WNT/ $\beta$-catenin pathway attenuates experimental emphysema. Am J Respir Crit Care Med 2011; 183: 723-733.

145 Van Durme YM, Eijgelsheim M, Joos GF, et al. Hedgehog-interacting protein is a COPD susceptibility gene: the Rotterdam Study. Eur Respir J 2010; 36: 89-95.

146 Nusse R. Wnt signaling and stem cell control. Cell Res 2008; 18: 523-527.

147 Wang R, Ahmed J, Wang G, et al. Down-regulation of the canonical Wnt $\beta$-catenin pathway in the airway epithelium of healthy smokers and smokers with COPD. PLoS One 2011; 6: e14793.

148 Jiang Z, Lao T, Qiu W, et al. A chronic obstructive pulmonary disease susceptibility gene, FAM13A, regulates protein stability of $\beta$-catenin. Am J Respir Crit Care Med 2016; 194: 185-197.

149 Uhl FE, Vierkotten S, Wagner DE, et al. Preclinical validation and imaging of Wnt-induced repair in human 3D lung tissue cultures. Eur Respir J 2015; 46: 1150-1166.

150 Webster RG. Immunity to influenza in the elderly. Vaccine 2000; 18: 1686-1689.

151 Budden KF, Gellatly SL, Wood DL, et al. Emerging pathogenic links between microbiota and the gut-lung axis. Nat Rev Microbiol 2017; 15: 55-63.

152 Mortaz E, Adcock IM, Ricciardolo FL, et al. Anti-inflammatory effects of Lactobacillus rahmnosus and Bifidobacterium breve on cigarette smoke activated human macrophages. PLoS One 2015; 10: e0136455.

153 Weiss DJ, Casaburi R, Flannery R, et al. A placebo-controlled, randomized trial of mesenchymal stem cells in COPD. Chest 2013; 143: 1590-1598.

$154 \mathrm{Gu}$ W, Song L, Li XM, et al. Mesenchymal stem cells alleviate airway inflammation and emphysema in COPD through down-regulation of cyclooxygenase-2 via p38 and ERK MAPK pathways. Sci Rep 2015; 5: 8733.

155 Ikonomou L, Freishtat RJ, Wagner DE, et al. The global emergence of unregulated stem cell treatments for respiratory diseases. Professional societies need to act. Ann Am Thorac Soc 2016; 13: 1205-1207. 